\title{
O PAPEL DA GERÊNCIA INTERMEDIÁRIA NA FORMAÇÃO DA ESTRATÉGIA
}

\section{RESUMO}

A literatura sobre a formação de estratégia é democrática, já que várias formas são reconhecidas e aceitas (Mintzberg, Ahlstrand \& Lampel, 2009). Os estudos qualitativos ajudam a compreender o que motiva um ou outro modo de formação de estratégia. Assim, essa pesquisa teve como objetivo analisar o processo de formação estratégica e o papel do nível gerencial, nesse processo. Seguiu-se a metodologia qualitativa, com o método de estudo de caso. As técnicas de coleta de dados foram entrevista semiestruturada, observação direta e análise de documentos. O caso em foco trata-se de um salão de beleza de médio porte da cidade de Florianópolis/SC. Dentre os principais resultados, aponta-se que as estratégias são formadas de forma integradora (deliberada e emergente), o que caracteriza o estilo middle-up-down (Nonaka, 1988), identificou-se ainda, de acordo com o framework integrativo de Hart (1992), três modos que evidenciam a formação da estratégia integradora: o comando, no qual a estratégia dirigida pelo líder ou por uma pequena equipe do topo; o transacional, em que por vezes o gestor e os membros da equipe trabalham juntos na formação da estratégia, dirigidos por processos internos e em comum acordo; e o genérico, sendo que, neste caso, a estratégia é dirigida pela ação dos membros da equipe e o gestor apenas apoia a decisão. Quanto aos papéis dos gerentes, verificou-se que a gerente administrativa atua de forma a sintetizar para os gestores de topo as informações coletadas com os colaboradores de nível operacional, e a gerente financeira atua como implementadora da estratégia deliberada.

Palavras-chave: Processo de Formação da Estratégia; Nível Gerencial; Setor da Beleza.

\section{THE ROLE OF THE INTERMEDIATE MANAGEMENT STRATEGY FORMATION}

\begin{abstract}
The literature on strategy formation is democratic, since various shapes are recognized and accepted (Mintzberg, Ahlstrand \& Lampel, 2009). Qualitative studies help to understand what motivates either strategy formation mode. Thus, this study aimed to analyze the process of strategy formation and the role of the management level in the process. qualitative methodology, the case study method followed. The data collection techniques were semi-structured interviews, direct observation and document analysis. The case in point it is a beauty salon Midsize city of Florianópolis / SC. Among the main results, points out that the strategies are formed in integrated manner (deliberate and emergent), which characterizes the middle-up-down style (Nonaka, 1988), it identified yet, according to the integrative framework Hart (1992), three modes that show the formation of the integrated approach: the command, in which the strategy directed by the leader or by a small team from the top; transactional, that sometimes the manager and team members work together in shaping the strategy, driven by internal processes and in agreement; and the generic, and in this case, the strategy is driven by the action of the members of the team and the manager only supports the decision. On the roles of managers, it was found that the administrative manager acts to synthesize for top managers the information collected with the operational level employees, and financial manager acts as implementer of deliberate strategy.
\end{abstract}

Keywords: Strategy Formation Process; Management Level; Beauty Industry. 


\section{EL PAPEL DE LA FORMACIÓN INTERMEDIA DE GESTIÓN DE LA ESTRATEGIA}

\section{RESUMEN}

La literatura sobre la formación de la estrategia es democrática, ya que varias formas son reconocidos y aceptados (Mintzberg, Ahlstrand y Lampel, 2009). Los estudios cualitativos ayudan a entender lo que motiva a cualquiera de los modos formación de la estrategia. Por lo tanto, este estudio tuvo como objetivo analizar el proceso de formación de la estrategia y el papel del nivel de gestión en el proceso. metodología cualitativa, el método de estudio de caso siguió. Las técnicas de recolección de datos fueron entrevistas semiestructuradas, observación directa y el análisis de documentos. El caso en cuestión es una ciudad de tamaño mediano del salón de belleza de Florianópolis / SC. Entre los principales resultados, señala que las estrategias se forman de manera integrada (emergente y deliberada), que caracteriza el estilo medio-arriba-abajo (Nonaka, 1988), es identificado por el momento, de acuerdo con el marco integrador Hart (1992), tres modos que muestran la formación del enfoque integrado: el comando, en el que la estrategia dirigida por el líder o por un pequeño equipo de la parte superior; transaccional, que a veces los miembros del usuario y equipo trabajan juntos en la conformación de la estrategia, impulsada por los procesos internos y de acuerdo; y el genérico, y en este caso, la estrategia es impulsado por la acción de los miembros del equipo y el gestor sólo es compatible con la decisión. En las funciones de las direcciones, se encontró que el gerente administrativo actúa para sintetizar los mejores gestores de la información recopilada con los empleados de nivel operativo, y actúa como gestor financiero ejecutor de la estrategia deliberada.

Palabras clave: Proceso de Formación de la Estrategia; Nivel de Gestión; Industria de la Belleza.

Daniela Macedo Venâncio ${ }^{1}$

Rosalia Barbosa Lavarda ${ }^{2}$ Gabriela Gonçalves Silveira Fiates ${ }^{3}$

\footnotetext{
${ }^{1}$ Mestre em Administração pela Universidade do Sul de Santa Catarina - UFSC. Professora da Universidade do Sul de Santa Catarina - UFSC. Brasil. E-mail: dani@fuzz.com.br

2 Doutora em Dirección de Empresas, Estrategias y Organización, pela Universitat de València - UV, España. Professora da Universidade do Sul de Santa Catarina - UFSC. Brasil. E-mail: rblavarda@gmail.com

3 Doutora em Engenharia de Produção pela Universidade Federal de Santa Catarina - UFSC. Professora da Universidade do Sul de Santa Catarina - UFSC. Brasil. E-mail: gabriela.fiates@ufsc.br
} 


\section{INTRODUÇÃO}

O conceito milenar de estratégia tem origem militar como um conjunto de ações deliberadas por generais para conquistar e ou controlar territórios (Mintzberg, Ahlstrand \& Lampel, 2009). No meio empresarial, as ações adotadas por uma organização para atingir seus objetivos de forma mais eficiente são definidas como estratégia (Chandler, 1962).

O ser e o fazer estratégico englobam não somente questões macroeconômicas relacionadas ao produto e mercado, mas também questões humanas sobre como as pessoas fazem a estratégia acontecer (Whittington, 2007). Nesse sentido, a literatura sobre o tema estratégia investiga os diversos níveis hierárquicos envolvidos no processo de formação da estratégia, nível operacional, nível médio (gerencial) e gestores do topo (Nonaka, 1988; Floyd \& Wooldridge, 1992).

Segundo Nonaka (1998), há três vertentes acerca do processo de formação da estratégia: racional, de estratégia deliberada; incremental, de estratégia emergente; e integradora, que reconhece ambas estratégias, deliberada e emergente, simultaneamente. Suspeita-se que o processo de formação de estratégia receba influências do ambiente, onde ambientes mais estáveis tendem a utilizar estratégias deliberadas com maior frequência que ambientes mais dinâmicos (Hart, 1992; Hart \& Banbury, 1994). Mintzberg, Ahlstrand e Lampel (2009) afirmam que a forma de desenvolver a estratégia pode ser influenciada por características diversas, como cultura, perfil do gestor e setor no qual a organização está inserida.

Ao considerar a assertiva de Bispo e Godoy (2014) de que a área estratégica é carente de estudos qualitativos que reconheçam as idiossincrasias das organizações e que respondam questões de pesquisas referentes ao modo como ocorre o fenômeno estratégico nas organizações, esta pesquisa objetiva analisar o processo de desenvolvimento estratégico e o papel do nível gerencial nesse processo.

Para tanto, a questão de pesquisa norteadora deste estudo é: Como ocorre o papel da gerência intermediária no processo de formação da estratégia?

Para responder à questão adotou-se a metodologia qualitativa por meio do método de estudo de caso único em uma empresa de serviços no setor da beleza. A seleção desse setor justifica-se pelo seu destaque na economia do Brasil, que é o terceiro país do mundo que mais fatura com essa indústria, empregando mais de dois milhões de pessoas nos salões de beleza, segundo a Associação Brasileira da Indústria de Higiene Pessoal, Perfumaria e Cosméticos (ABIHPEC, 2014).

\section{PROCESSO DE FORMAÇÃO DA ESTRATÉGIA}

Cada organização parece ter características próprias que refletem sua forma de desenvolver suas estratégias, mas com frequência esse processo é apresentado em termos dicotômicos: racional $\mathrm{x}$ incremental ou formulação $\mathrm{x}$ implementação (Angonese; Lavarda; Lavarda, 2013).

Com intenção de capturar diferentes pontos de vista sobre o processo de formação da estratégia, Mintzberg, Ahlstrand e Lampel, (2009) categorizam os estudos em dez escolas: três com abordagem prescritiva e de conte (design, planejamento e posicionamento); e sete com abordagem descritiva e processual (empreendedora, cognitiva, do aprendizado, do poder, cultural e da configuração). A partir da leitura das escolas, infere-se que o pensar estrategicamente pode variar de acordo com o perfil do estrategista e do ambiente, que pode ser individual ou coletivo, analítico ou voltado para ação. Em comum, todas as teorias de tais escolas visam compreender qual a melhor forma de mudar de um ponto A para um ponto B, de forma eficaz, com menor custo e maior velocidade para tornar-se mais competitivo.

Mintzberg e Waters (1985) definem estratégia como um plano para delinear futuras ações, processo que tende a ser analítico ao traçar metas de longo alcance e desenvolver um plano de ação para a organização. Eles identificam dois tipos de estratégias, a deliberada e a emergente. A primeira define o plano antes da execução, costuma ser top-down e possui as seguintes características: clareza no objetivo final, informações conhecidas por todos os envolvidos, desenvolve-se conforme o planejado, sem interferências externas, o que exige um estudo prévio do ambiente. A segunda ocorre sem planejamento, durante a execução da ação, tende a emergir de uma ação coletiva, é bottom-up. Os autores afirmam que ambas fazem parte do dia a dia das organizações, pois se apresentam misturadas, e não em formas puras. Assim, eles identificam um terceiro tipo de estratégia, a integradora, que contempla a deliberada e a emergente. $\mathrm{Ou}$ seja, a estratégia integradora defende que ambas são desenvolvidas conforme as necessidades ou características da organização. Mintzberg e Waters (1985) desenvolveram ainda uma tipologia que envolve oito tipos de estratégia: planejada, empreendedora, ideológica, guarda-chuva, de processo, não conectada, de consenso e imposta, Figura 1. 
Figura 1 - Tipologia de formação de estratégia

\begin{tabular}{|c|c|c|}
\hline ESTRATÉGIA & DEFINIÇÃO DA ESTRATÉGIA & TIPO \\
\hline Planejada & $\begin{array}{l}\text { A formulação da estratégia cabe à alta gerência e sua execução deve ser } \\
\text { conforme o planejado. }\end{array}$ & Deliberada \\
\hline Empreendedora & $\begin{array}{l}\text { A visão geral da estratégia é definida através da visão de um indivíduo, } \\
\text { podendo receber modificações no decorrer da implementação. }\end{array}$ & Integradora \\
\hline Ideológica & $\begin{array}{l}\text { As visões podem ser individuais ou coletivas. Ocorre quando os membros } \\
\text { de uma organização compartilham uma visão e a perseguem. }\end{array}$ & Deliberada \\
\hline Guarda-chuva & $\begin{array}{l}\text { O líder possui um controle parcial da estratégia, ele define limites e os } \\
\text { demais atores trabalham dentro desse contexto. }\end{array}$ & Integradora \\
\hline De processo & $\begin{array}{c}\text { A estratégia é definida pelos líderes e os atores podem manobrar a execução } \\
\text { para atingir os resultados. }\end{array}$ & Integradora \\
\hline Não conectada & $\begin{array}{c}\text { Um indivíduo ou uma parte da organização cria seu próprio padrão e fluxo } \\
\text { de aços. }\end{array}$ & Emergente \\
\hline De consenso & $\begin{array}{l}\text { Diferentes atores convergem para uma mesma ideia ou um mesmo padrão } \\
\text { sem a necessidade de intervenção da direção geral. }\end{array}$ & Emergente \\
\hline Imposta & $\begin{array}{c}\text { Ocorre quando o ambiente externo força a organização a mudar uma } \\
\text { estratégia. }\end{array}$ & Deliberada \\
\hline
\end{tabular}

Fonte: Mintzberg e Waters (1985)

Nesse contexto, o conceito de formação da estratégia deve ser visto a partir da concepção de processo que contempla níveis hierárquicos distintos ao ocorrer a partir de diferentes níveis, de cima para baixo, de baixo para cima ou do meio para cima e para baixo, seguindo o conceito de guarda-chuva de Mintzberg e Waters (1985) ou middle-up-down de Nonaka (1988). Parte da literatura considera a participação dos diferentes níveis hierárquicos no processo da formação da estratégia, porém grande parte dos estudos empíricos investiga apenas a atuação dos gestores de topo, em que eles deliberam e os demais executam, com foco em estratégias deliberadas de planejamento formal (Mantere, 2008).

Hart (1992) propôs um framework integrativo que contempla informações como: estilo de gestão, papel dos gestores e papel dos membros organizacionais. Essa estrutura integrativa é composta por cinco modos de gestão: comando, simbólico, racional, transacional e generativo, Figura 2.

De acordo com Hart (1992), não há um modo correto ou errado para processar uma estratégia, porém o autor levanta algumas proposições a respeito da relação entre o modo de processar a estratégia e o desempenho alcançado, conceituando desempenho como: o retorno financeiro (sobre ativos, vendas); o crescimento; a diversificação; e a eficácia organizacional (satisfação, qualidade, responsabilidade social). Nesse sentido, organizações de pequeno porte atuam em ambientes relativamente simples, então o modo de comando será associado com maior desempenho. 
Figura 2 - Framework integrativo

\begin{tabular}{|c|c|c|c|c|c|}
\hline Tipologia & Comando & Simbólico & Racional & Transacional & Generativo \\
\hline Estilo & $\begin{array}{l}\text { (Imperial) } \\
\text { Estratégia } \\
\text { dirigida pelo } \\
\text { líder ou por } \\
\text { uma pequena } \\
\text { equipe do } \\
\text { topo }\end{array}$ & $\begin{array}{l}\text { (Cultural) } \\
\text { Estratégia dirigida } \\
\text { pela missão e } \\
\text { visão do futuro }\end{array}$ & $\begin{array}{l}\text { (Analítico) } \\
\text { Estratégia } \\
\text { dirigida por } \\
\text { uma estrutura } \\
\text { formal }\end{array}$ & $\begin{array}{l}\text { (Processual) } \\
\text { Estratégia } \\
\text { dirigida pelos } \\
\text { processos } \\
\text { internos e em } \\
\text { comum acordo }\end{array}$ & $\begin{array}{c}\text { (Orgânico) } \\
\text { Estratégia } \\
\text { dirigida pela } \\
\text { iniciativa dos } \\
\text { atores } \\
\text { organizacionais }\end{array}$ \\
\hline $\begin{array}{l}\text { Papel dos } \\
\text { gestores } \\
\text { de topo }\end{array}$ & $\begin{array}{l}\text { Comandante } \\
\text { Proporcionar } \\
\text { direção }\end{array}$ & $\begin{array}{c}\text { Treinador } \\
\text { Motivar e inspirar }\end{array}$ & $\begin{array}{l}\text { Chefe } \\
\text { Avaliar e } \\
\text { controlar }\end{array}$ & $\begin{array}{l}\text { Facilitador } \\
\text { Empoderar e } \\
\text { capacitar }\end{array}$ & $\begin{array}{c}\text { Patrocinador } \\
\text { Endossar e } \\
\text { apoiar }\end{array}$ \\
\hline $\begin{array}{c}\text { Papel dos } \\
\text { membros } \\
\text { organiza- } \\
\text { cionais }\end{array}$ & $\begin{array}{c}\text { Soldado } \\
\text { Obedecer às } \\
\text { ordens }\end{array}$ & $\begin{array}{c}\text { Jogador } \\
\text { Responder aos } \\
\text { desafios }\end{array}$ & $\begin{array}{c}\text { Subordinado } \\
\text { Seguir o } \\
\text { sistema }\end{array}$ & $\begin{array}{l}\text { Participante } \\
\text { Aprender e } \\
\text { melhorar }\end{array}$ & $\begin{array}{l}\text { Intraempreen- } \\
\text { dedor } \\
\text { Experimentar e } \\
\text { assumir riscos }\end{array}$ \\
\hline
\end{tabular}

Fonte: Hart (1992)

Entre organizações que estão crescendo rapidamente em ambientes super dinâmicos, o modo simbólico tende a oferecer maior desempenho. Em empresas de pequeno e médio porte que atuam num ambiente relativamente estável, o modo racional será associado com maior desempenho. Por sua vez, em empresas de grande porte, indústrias maduras e com interações complexas, o modo transacional trará maior desempenho. O generativo será o modo prevalente entre as empresas que competem em ambientes turbulentos (complexos e em rápida mutação), em que a prospecção é importante para o sucesso competitivo, e será associado com maior desempenho nessas situações (Hart, 1992 \& Hart \& Banbury, 1994).

Uma organização pode mesclar diferentes modos de gestão e as empresas capazes de desenvolver competências em vários modos (comando, simbólico, racional, trasacional e ou generativo), podem aproveitar seus recursos de maneira mais complexa, gerando assim uma vantagem competitiva. Mintzberg, Ahlstrand e Lampel (2009) afirmam que a soma da utilização de um planejamento estratégico formal com a possibilidade de os membros organizacionais desenvolverem ações autônomas apresenta efeitos positivos no desempenho da organização.

Nessa perspectiva, Anganose, Lavarda e Lavarda (2013) investigaram como os modelos de implementação da estratégia, propostos por Hart (1992) são aplicados em duas organizações e como esses modos são influenciados por variáveis contingenciais, como a estabilidade ou instabilidade do ambiente em que a empresa atua. Pelos resultados obtidos, verificouse que as empresas estudadas adotam uma combinação dos diferentes modelos de implementar a estratégia, e que quanto mais estável o ambiente maior a probabilidade de que a organização opte pelos modelos comando ou racional ou, ainda, adote uma combinação entre eles.

\subsection{O Papel do Nível Gerencial}

A tipologia dos papéis que envolvem o nível gerencial é apresentada por Floyd e Wooldridge (1992). Nela, a gerência pode ser definida como a coordenação das atividades do dia a dia de uma unidade organizacional com as atividades dos grupos verticalmente relacionados. Tradicionalmente, os gerentes de nível médio não eram considerados parte do processo de estratégia, exceto ao fornecer insumos informativos e orientar implementação (Floyd \& Wooldridge, 1992). Floyd e Wooldridge (1992) investigaram o envolvimento estratégico de 259 gerentes em 25 organizações e apresentaram uma tipologia que envolve quatro papéis de nível intermediário: defensor, facilitador, sintetizador e implementador, Figura 3. 
Figura 3 - A tipologia do envolvimento da gerência intermediária na estratégia

\begin{tabular}{|c|c|c|}
\hline 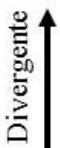 & $\begin{array}{l}\text { Defendendo } \\
\text { alternativas } \\
\text { DEFENSOR }\end{array}$ & $\begin{array}{c}\text { Facilitando a } \\
\text { adaptação } \\
\text { FACILITADOR }\end{array}$ \\
\hline 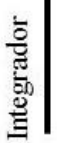 & $\begin{array}{c}\text { Sintetizando } \\
\text { informações } \\
\text { SINTETIZADOR }\end{array}$ & $\begin{array}{l}\text { Implementando a } \\
\text { estratégia deliberada } \\
\text { IMPLEMENTADOR }\end{array}$ \\
\hline
\end{tabular}

Fonte: Adaptado de Floyd e Wooldridge (1992)

De acordo com a Figura 1, os gerentes intermediários podem atuar como divergentes ou integradores. Como divergentes ao defender as alternativas impostas pelos gestores de topo, levando até eles informações que contra argumentem a intenção da estratégia; podem ainda ser facilitadores, adaptando a estratégia deliberada para que ela seja implementada com mais facilidade. Como integradores eles podem sintetizar as informações internas e externas e levá-las até a alta direção, o que pode afetar a percepção dos gestores, que podem ou não modificar a estratégia; podem também atuar como implementadores da estratégia deliberada ao ajustar, motivar e inspirar a equipe com o objetivo de ter sucesso na implementação (Floyd \& Wooldridge, 1992).

De acordo com Floyd \& Wooldridge (1992), os gerentes que operam levando informações da equipe operacional para os gestores do topo participam mais ativamente do processo de formação da estratégia, o contrário ocorre quando os gerentes atuam de cima para baixo, nesse caso eles participam mais como implementadores de uma estratégia deliberada.

Com base na tipologia evidenciada por Floyd \& Wooldridge (1992), Franzon, Oliveira e Lavarda (2012) fizeram um estudo com o objetivo de identificar a atuação dos gerentes intermediários no processo de formulação e implementação de estratégia e encontraram que eles têm um papel importante tanto na formação como na implementação da estratégia; os estudos apontam ainda que, dependendo da situação, um mesmo gerente pode atuar como divergente ou como facilitador da estratégia.

Após revisar a literatura sobre os processos de formação de estratégia e o papel do nível gerencial nesse processo (Luz, Gobo \& Lavarda, 2013) emerge uma proposição teórica, também decorrente da busca por responder à questão inicial de pesquisa:

Proposição: A formação da estratégia é integradora - middle-up-down quando o gerente intermediário desempenha um papel integrador (sintetizando a informação e implementando a estratégia deliberada) sendo autônomo e participativo simultaneamente.

\subsection{Setor da Beleza}

O setor da beleza vem crescendo nos últimos dez anos em alguns países, especialmente nos países ocidentais, segundo a Associação Brasileira da Indústria de Higiene Pessoal, Perfumaria e Cosméticos (ABIHPEC, 2014). De acordo com a ABIHPEC, esse crescimento deve-se, dentre outros motivos, à consolidação da mulher no mercado de trabalho e em postos com salários mais altos, ao aumento da vaidade masculina e ao aumento da população da terceira idade.

O Brasil é responsável por $10,1 \%$ do faturamento mundial, ficando atrás somente dos Estados Unidos e do Japão (Martins et al., 2014; Venâncio et al., 2015). Em 2014, o setor faturou mais de 100 bilhões de reais no país, a ABIHPEC (2014) divulga que esse é um dos poucos mercados não afetados pela crise econômica. As pequenas e microempresas representam $98,9 \%$ do parque industrial brasileiro de higiene pessoal, perfumaria e cosméticos (ABIHPEC, 2014). A ABIHPEC divide o setor em quatro canais de distribuição: varejo tradicional, varejo especializado (franquias), vendas diretas e salões de beleza.

Os salões de beleza fazem parte do setor de serviços que apresentam características como: (i) intangibilidade, impossibilidade de estocagem de serviços; (ii) heterogeneidade ou variabilidade, nenhum serviço é prestado duas ou mais vezes de forma idêntica; (iii) perecibilidade ou oportunidade perdida, ou seja, desequilíbrio entre a capacidade e a demanda (Zeithaml \& Bitner, 2003; Fitzsimmons \& Fitzsimmons, 2010). Outra característica é a relação próxima entre o receptor (cliente) e o prestador do serviço (cabeleireiro, manicure, esteticista), trata-se de um serviço de intenso toque e com grande intimidade, existe uma interação social próxima e amigável entre cliente e funcionário (Nogueira, Souza \& Nunes, 2009; Ribeiro, Thiesen \& Tinoco, 2013).

Em relação aos contratos de trabalho firmados entre os membros da equipe e os proprietários da empresa, é comum existir dois tipos, o efetivo (carteira assinada) e o autônomo (contratos de locação ou parceria). Geralmente, possuem carteira assinada recepcionista, telefonista, estoquista, serviços gerais, manobrista, gerentes, supervisores, caixa, dentre outras 
funções administrativas. Enquanto os profissionais autônomos costumam ser manicures, cabeleireiros, barbeiros, esteticistas, maquiadores e depiladores, recebendo um percentual sobre sua produção; cada salão de beleza tem seu valor de repasse e modelo de contrato de parceria específicos (Martins et al., 2014; Venâncio et al., 2015). Estima-se que aproximadamente $70 \%$ dos membros de uma equipe de um salão de beleza são compostos por indivíduos autônomos (Venancio et al., 2015).

Em pesquisa sobre o comprometimento dos profissionais que atuam em salões de beleza com a organização e com o trabalho desempenhado, constatou-se que os profissionais autônomos são mais comprometidos quando comparados aos efetivos, tanto com seu trabalho como com a organização (Venâncio et al., 2015). Os autores indicam que o compromisso elevado está diretamente relacionado à escolha da autonomia, pois esses profissionais precisam estar comprometidos com seu trabalho se desejam continuar na profissão, ou seja, o esforço para melhorar seu trabalho mostra-se mais evidente, até mesmo por questão de sobrevivência.

Com relação às ações estratégicas, Ribeiro, Thiesen e Tinoco (2013), em uma pesquisa sobre o que os clientes percebem como qualidade num salão de beleza, concluem que estes procuram profissionais empenhados em realizar o serviço da forma requerida por eles, o que envolve competência técnica, entendimento de suas necessidades, exatidão do serviço realizado e atenção dispensada. Para que esses critérios sejam satisfeitos, é necessário que o salão garanta condições para o bom atendimento e desempenho no serviço, com higiene adequada e individualização dos utensílios, equipamentos e utensílios modernos e limpeza do ambiente. Observou-se ainda que os clientes de salão de beleza priorizam atributos relacionados às competências dos funcionários de linha de frente e outros atributos facilitadores, como localização conveniente, disponibilidade de estacionamento, horários convenientes de atendimento e possibilidade de marcar hora.

No tocante ao comportamento estratégico de gestores de salões de beleza, Gallas et al. (2015) investigaram uma amostra de 254 empresas a partir do modelo de Miles e Snow (1978), que apresenta quatro tipologias estratégicas: defensiva, prospectora, analítica e reativa. A pesquisa identificou que o comportamento estratégico que mais se destaca no setor é o defensor, caracterizado pela baixa ousadia na procura de novas oportunidades em empresas que visam eficiência dentro de um padrão pré-determinado e que, frequentemente, utilizam planejamento estratégico e controles centralizados.

\section{METODOLOGIA}

Esta pesquisa utiliza abordagem qualitativa (Yin, 2015), descritiva e o método de pesquisa é o estudo de caso único (Eisenhardt, 1989). As pesquisas qualitativas são apropriadas para responder problemas de pesquisa que buscam entender como um fenômeno ocorre, no caso: Como ocorre o processo de formação da estratégia e como são desempenhados os papeis dos gerentes intermediários nesse processo?

O estudo de caso único é apropriado para responder questões sobre fenômenos de pouco controle, que só poderão ser analisados dentro de algum contexto de vida real (Eisenhardt, 1989; Yin, 2015). Assim, a seleção do caso se justifica pela importância econômica do setor no qual está inserido; o caso selecionado para estudo é um salão de beleza de médio porte estabelecido no mercado há 16 anos, situado na cidade de Florianópolis/SC. A seleção desse setor (setor da beleza) justifica-se pelo seu destaque na economia do Brasil, que é o terceiro país do mundo que mais fatura com essa indústria, empregando mais de dois milhões de pessoas nos salões de beleza, segundo a Associação Brasileira da Indústria de Higiene Pessoal, Perfumaria e Cosméticos (ABIHPEC, 2014).

Além disso, outros três fatores justificam a seleção do caso: (i) o fato de a empresa ter os três níveis hierárquicos bem definidos, ponto não muito comum nesse tipo de empresa; a diretoria da empresa é composta por dois diretores, um é responsável pela administração geral, enquanto o outro lida com questões técnicas inerentes aos serviços prestados. A empresa conta ainda com 44 colaboradores (dez com carteira assinada e 34 com contratos de parceria). (ii) a diretora/proprietária da empresa é administradora e possui pós-graduação em administração, o que leva a empresa a ter um planejamento estratégico estruturado (apresentado na análise dos resultados); (iii) interesse, disponibilidade e acessibilidade aos dados necessários para a pesquisa. Optou-se por não divulgar o nome da empresa, retratando-a nesta pesquisa como "salão de beleza pesquisado".

O protocolo de pesquisa, com a definição das técnicas de coleta de dados e os critérios para interpretação e análise dos resultados, a partir de Yin (2015), considera como técnica de coleta de dados: análise de documentos (arquivos), entrevistas e observação direta (e/ou observação participante), as quais propiciaram a triangulação dos dados para efeito de ganho de confiabilidade, já que oferecem percepções variadas do mesmo fenômeno.

Desta forma, esta pesquisa contou com: (i) entrevistas em profundidade: entrevista semiestruturada, direta, pessoal, executada por um entrevistador treinado, para descobrir motivações, crenças, atitudes e sensações a respeito da formação da estratégia; foram entrevistados nove colaboradores da empresa (Tabela 1); (ii) análise de documentos: planejamento estratégico, balancetes, campanhas de marketing, atas de reuniões, resultados de pesquisas 
feitas com clientes e funcionários em 2014; e (iii) observação direta: os pesquisadores acompanharam as ações estratégicas desenvolvidas na empresa e a atuação dos diferentes níveis hierárquicos em um período de 45 dias (16 de maio a 30 de junho de 2015).

Tabela 1 - Relação dos entrevistados

\begin{tabular}{|c|c|c|c|}
\hline Nível & \multirow{2}{*}{ Quantidade } & Função & Tempo de entrevista \\
\hline Gestor do topo & 1 & Diretora Administrativa & 49 minutos \\
\hline Nível médio & 2 & Gerente financeira & 61 minutos \\
& & Gerente administrativa & 67 minutos \\
\hline Nível operacional & & Auxiliar de escritório & 52 minutos \\
& 6 & Auxiliar de cabeleireiro & 55 minutos \\
& & Cabeleireiro & 49 minutos \\
& & Depiladora & 48 minutos \\
\hline Total & 9 & Esteticista & 433 minutos \\
\hline
\end{tabular}

Fonte: Elaboração própria

As entrevistas ocorreram entre os dias 19 e 23 de junho de 2015; foram gravadas e tiveram seu uso autorizado para a pesquisa pelos participantes por meio da assinatura de um termo de consentimento. Conforme dito, a entrevista contou com o apoio de um roteiro, com perguntas abertas, desenvolvido a partir das dimensões apontadas no Figura 4. As dimensões de análise (DA) seguem os conceitos de categorias de análise de Kerlinger (1979).

Por ser relevante compreender como acontece a participação dos diversos integrantes da organização na formação estratégica, para analisar como ocorre o processo de implementação da estratégia no setor da beleza levou-se em consideração três diferentes níveis hierárquicos da organização: gestores (alta direção), gerentes e equipe operacional.

Figura 4 - Proposições, dimensões de análise e conceitos

\begin{tabular}{|c|c|c|c|}
\hline Autor & Proposição & Dimensões de Análise (DA) & Conceitos \\
\hline 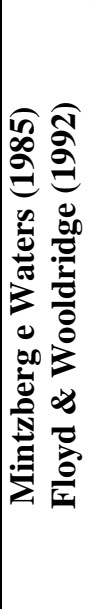 & $\begin{array}{l}\text { A formação da estratégia é } \\
\text { integradora - middle-up-down } \\
\text { quando o gerente intermediário } \\
\text { desempenha um papel integrador } \\
\text { (sintetizando a informação e } \\
\text { implementando a estratégia } \\
\text { deliberada) sendo autônomo e } \\
\text { participativo simultaneamente. }\end{array}$ & $\begin{array}{l}\text { DA1. Estratégia deliberada - } \\
\text { top down } \\
\text { DA2.Estratégia emergente - } \\
\text { buttom-up. } \\
\text { DA3Estratégia intergradora - } \\
\text { middle-up-down } \\
\text { DA4. Gerente integrador }\end{array}$ & $\begin{array}{l}\text { DA1: a formulação da estratégia cabe à } \\
\text { alta direção. A estratégia deve ser } \\
\text { executada conforme o planejado. } \\
\text { DA2: a formação ocorre sem ter sido } \\
\text { planejada previamente. } \\
\text { DA3: a direção possui um controle } \\
\text { parcial da estratégia, define limites e os } \\
\text { demais atores trabalham dentro desse } \\
\text { contexto. } \\
\text { DA4: o gerente integrador é sintetizador, } \\
\text { categorizando ideias da equipe, } \\
\text { sintetizando e informando-as à alta } \\
\text { direção; e implementador: o gerente } \\
\text { ajusta a estratégia, motiva e inspira a } \\
\text { equipe a alcançá-la. }\end{array}$ \\
\hline
\end{tabular}

Fonte: Elaboração própria

Para a análise dos dados foi usada a tática pattern matching (Trochim, 1989), a qual é indicada para comparar acontecimentos, comportamentos, padrões e circunstância identificados na pesquisa (empírica) com o marco teórico revisado permitindo avaliar (confirmar ou rejeitar) a proposição de pesquisa. Esta tática permite a geração de explicações uma vez que busca explicar os acontecimentos com base na sua interação com outros, ou novas circunstâncias que se apresentam no contexto de forma narrativa. Assim, de forma complementar se adotou a análise da narrativa que, por sua vez, define-se como 
um entendimento geral (todo) partindo da sua totalidade para as particularidades do fenômeno estudado (Godoi, Bandeira-de-Melo E Silva, 2006). Estas técnicas são as mais recomendadas para esta investigação, por se propor a analisar como ocorre o processo de formação da estratégia e o papel do nível gerencial nesse processo, estabelecendo a possibilidade de comparação entre a teoria e a prática (Trochim, 1989).

\section{RESULTADOS E DISCUSSÀO}

Esta seção apresenta como ocorre o processo de formação da estratégia na organização pesquisada e como são desempenhados os papeis do gerente intermediário. As narrativas dos participantes são classificadas da seguinte forma: gestor de topo, gerente administrativo, gerente financeiro e nível operacional. A apresentação dos resultados segue as dimensões de análise.

\section{DA1: Processo de formação da estratégia deliberada}

O salão de beleza pesquisado possui um planejamento formal estruturado. A empresa tem por norma reformular o planejamento anualmente, nas palavras da gerente administrativa: "fazemos um planejamento por ano, alguns pontos se repetem, como a questão dos treinamentos técnicos e de desenvolvimento pessoal, mas a cada ano uma nova variável é inserida, novas metas são formuladas". O planejamento para 2015 foi desenhado entre dezembro de 2014 e fevereiro de 2015.

A partir das análises documentais realizadas, verificou-se que o planejamento estratégico da organização é dividido em oito categorias: competências técnicas, atendimento diferenciado, aparência das instalações, tecnologia digital, ambiente de trabalho, ações sociais, parcerias e custos. Cada categoria possui suas metas, suas ações e seus resultados esperados. Esses blocos foram definidos a partir de informações coletadas com clientes, colaboradores, fornecedores, órgãos do ramo e de uma análise interna, e posteriormente compilados em uma análise SWOT - matriz de Forças (Strengths), Fraquezas (Weaknesses), Oportunidades (Opportunities) e Ameaças (Threats). As informações coletadas foram analisadas pelos gestores de topo e gerentes, que formaram os blocos citados.

As estratégias de cada bloco foram desenvolvidas com a participação de todos os níveis hierárquicos da empresa, conforme declaração do gestor, "coletamos os dados, reunimos as informações e convidamos todos da equipe a participarem do planejamento" (gestor de topo). Essa construção em conjunto definiu 49 ações estratégicas (deliberadas) a serem desenvolvidas em 2015, além do crescimento esperado para esse ano, que é de $12 \%$ em relação a 2014. A Figura 5 apresenta o processo de formação da estratégia deliberada na empresa.

As ações deliberadas são acompanhadas periodicamente pela diretora administrativa e pelos gerentes; a partir disso, algumas ações pré-definidas passam a ser canceladas, outras, incrementadas, "tínhamos com meta disponibilizar Ipads para os clientes utilizarem durante $o$ atendimento, mas percebemos que esse não seria um bom investimento, já que boa parte das clientes utilizam os seus próprios celulares" (gerente financeira). A análise dos documentos mostra que das 49 ações definidas em fevereiro de 2015, nove foram descartadas até 30 de junho de 2015.

Percebe-se que o planejamento estratégico conta com a participação de diferentes níveis hierárquicos, mas a estratégia é formada com o consentimento do gestor de topo, indo ao encontro da estratégia guarda-chuva, definida por Mintzberg e Waters (1985). A formação de estratégias emergentes é comum na empresa estudada. 
Figura 5 - Processo de formação da estratégia deliberada na empresa

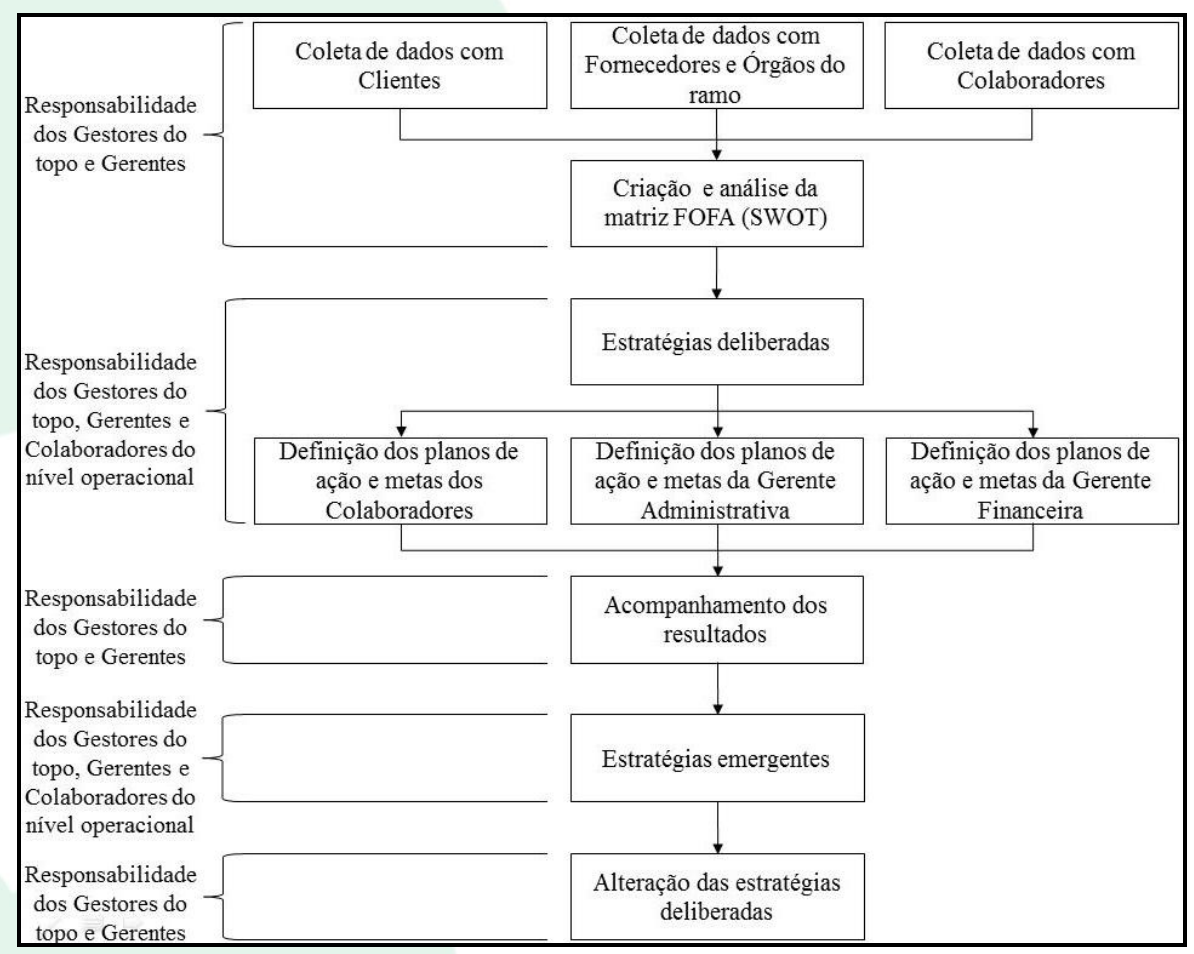

Fonte: Elaboração própria

DA2: O processo de formação da estratégia emergente

O dia a dia do salão é bem movimentado, circulam em média 1500 clientes por mês. O espaço é amplo e, muitas vezes, os profissionais atendem em conjunto (por exemplo, um executa o serviço de manicure, enquanto o outro o de escova). A relação entre cliente e profissional é bem próxima, fazendo com que os clientes se sintam à vontade para dar sugestões de melhorias, corroborando com os achados de Nogueira, Souza e Nunes (2009) e Ribeiro, Thiesen e Tinoco (2013). Além disso, como forma de ouvir o cliente, a empresa adotou uma ferramenta chamada cliente oculto, na qual o cliente avalia (de forma sigilosa) o serviço prestado de acordo com suas impressões e experiências vivenciadas.

Dessa interação com o cliente emergem algumas estratégias, por exemplo, em 2015 as manicures e depiladoras passaram a ressaltar em suas falas o uso de materiais descartáveis feito pela empresa, reflexo da observação do relatório de um cliente oculto: "fiquei em dúvida com relação a esterilização dos materiais. Por exemplo, ela utilizou uma pinça, mas não sei se foi descartável" (cliente oculto - dados documentais).
Além da interação com o cliente, percebeu-se que é forte a interação entre os membros da equipe operacional, desse convívio também emergem estratégias: "quando estamos sem movimento, vamos para a cozinha, lá pensamos em formas de vender mais serviços" (colaborador do nível operacional), outro colaborador diz: "na semana passada, em conversa com dois colegas, tivemos a ideia de criarmos vídeos de $15 \mathrm{~s}$ para postar em redes sociais" (colaborador do nível operacional). O fato de os prestadores de serviços serem autônomos e, consequentemente, terem seus recebimentos vinculados a sua produção, instiga-os a pensar em formas de atrair mais clientes (Venâncio et al., 2015).

Outra forma de emergir estratégia acontece durante as reuniões dirigidas pela gerência ou pelos gestores do topo. Mensalmente, toda a equipe (todos os níveis hierárquicos) reúne-se para definir as ações de marketing do mês, "nos reunimos para definir as promoções, pois elas afetarão diretamente os profissionais. Já caímos no erro de criarmos uma promoção sem consultar a equipe e o resultado não foi positivo, ou a equipe não se interessa em vender ou, pior ainda, ficavam insatisfeitos com a promoção" (gerente administrativa).

A Figura 6 apresenta o processo de formação da estratégia emergente na empresa estudada. 
Figura 6 - Processo de formação das estratégias emergentes na empresa

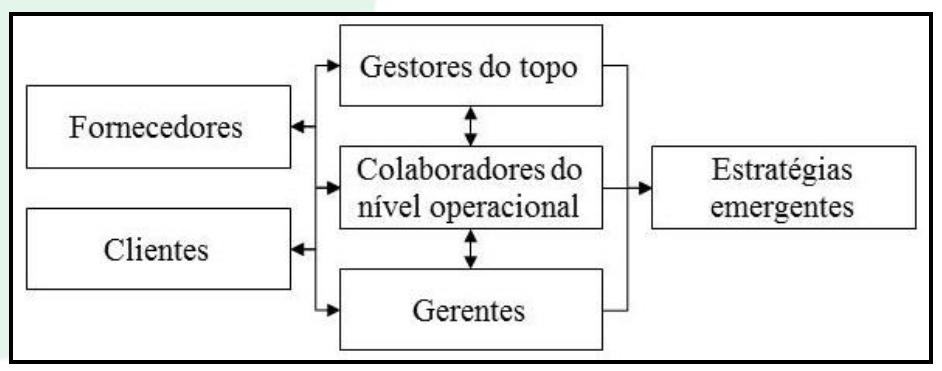

Fonte: Dados da pesquisa

Alguns fornecedores também são fontes de estratégias emergentes, principalmente no que diz respeito à introdução de novos serviços e/ou produtos, "a introdução de novos serviços e produtos está relacionada com lançamentos disponíveis no mercado" (gestor de topo). As inovações disponibilizadas por eles são oferecidas para diversos salões, baixando assim o nível de competitividade da estratégia (Barney \& Hesterly, 2007). Portanto, parece que as estratégias que proporcionam maior vantagem competitiva são as desenvolvidas a partir da interação entre a equipe e seus clientes (Ribeiro, Thiesen \& Tinoco, 2013; Martins et al, 2014).

\section{DA3: O processo de formação da estratégia integrador}

$\mathrm{Na}$ formação da estratégia integradora a direção possui um controle parcial da estratégia, define limites e os demais atores trabalham dentro desse contexto (segundo Mintzberg \& Waters, 1985). Na empresa a opinião e a participação dos profissionais autônomos têm grande relevância, pois eles tanto experimentam o impacto das estratégias quanto colaboram de maneira interessada em sua elaboração, de modo que o sucesso delas está normalmente atrelado a sua aceitação e ao seu comprometimento (Venâncio et al., 2015). Porém, existem limites impostos pelos gestores de topo, "temos um objetivo a ser alcançado, as ideias que não vão ao encontro desse objetivo serão descartadas" (gestor de topo).

As estratégias financeiras estão mais vinculadas à gerente financeira, pois essas decisões envolvem conhecimentos mais aprofundados sobre finanças e planejamento financeiro, "as pessoas pensam que a empresa tem recursos infinitos, mas isso está longe de ser verdade, trabalhamos com uma margem pequena, e toda decisão de investimento precisa ser bem pensada" (gerente financeira).

A estratégia é discutida principalmente entre os diretores e as gerentes, mas isso não significa que esteja restrita a eles, a opinião de todos os colaboradores é levada em consideração na definição das diretrizes da empresa, "Eu sempre percebi um planejamento muito forte vindo do pessoal da direção, vindo dos donos e das pessoas que fazem parte da administração, mas não só partindo deles, percebo também que eles sempre escutam a equipe" (colaborador do nível operacional).

O plano estratégico elaborado serve como embasamento para as reuniões realizadas entre a diretora administrativa e as gerentes, nesses momentos os planos de ação são acompanhados e discutidos para que se compreenda se as definições estratégicas estão sendo implementadas e, principalmente, se os resultados estão surgindo conforme o esperado (Nonaka, 1988).

Eu preciso ter um "norte", e esse plano acaba sendo a minha linha de trabalho, então uma vez por semana eu paro e olho esse plano para que as minhas ações da semana sejam pautadas em cima disso, e esse plano abrange todas as áreas da empresa e, com a diretora, a gente vê de tempos em tempos o que eu estou fazendo em cima desse plano e o que vai surgindo no caminho (gerente administrativa, 2015).

Essa dinâmica possui características de uma estratégia do tipo guarda-chuva, em que os diretores conduzem a construção da estratégia, mas delegam as ações à gerente administrativa, que deve executar a estratégia deliberada e possui liberdade para sugerir e executar estratégias emergentes (Mintzberg \& Waters, 1985).

Os diretores influenciam na delimitação da estratégia em comum acordo com a gerência, os colaboradores e a legislação vigente, configurando um modelo de gestão com elementos mecânicos e orgânicos, delineados por decisões de caráter middleup-down (Nonaka, 1988).

Adicionalmente, considerando os cinco modos de desenvolvimento e implementação estratégica definidos por Hart (1992), foi possível observar na empresa estudada elementos de quase todos os modos, com destaque aos modos comando, transacional e generativo, o que também leva a caracterização de integração do processo.

A gestora de topo tem um envolvimento grande com a definição da estratégia deliberada, como visto na seção sobre a formação da estratégia deliberada, evidenciando, em parte, um modo comando 
baseado principalmente nas decisões da diretoria. O modo comando é caracterizado pela decisão do gestor de topo, baseado em evidências, e em análises, "temos um sistema em que acompanho o resultado financeiro da empresa, perfil de compras do cliente, produção por área de trabalho, essas informações me ajudam na tomada de decisão" (gestor de topo). Outra questão que favorece o modo comando é o ambiente com tarefas de baixa complexidade no qual a empresa atua (Hart, 1992; Hart; Banbury, 1994), nas palavras " nossas rotinas de trabalho não sofrem muitas mudanças, fazer uma unha, cortar um cabelo, são processos repetitivos" (colaborador nível operacional).

Boa parte da equipe é composta por profissionais autônomos, a adesão deles na formação da estratégia é de suma importância. Nesse aspecto o modo transacional é evidente, uma vez que os colaboradores são incentivados a participarem da construção da estratégia, nas palavras de um colaborador de nível operacional: "A empresa quer despertar a pró-atividade e a participação da gente nas decisões, nós temos que fazer a nossa parte e eles nos dão autonomia para isso". Segundo a gerente administrativa, "as estratégias de marketing são formadas em comum acordo, os profissionais têm liberdade para aceitarem ou não uma campanha".

O modo generativo também está diretamente ligado à formação de estratégias de marketing. A empresa investe pouco em marketing externo, opta por campanhas internas, que são dependentes da participação de todos os agentes da empresa. Algumas estratégias emergem da equipe operacional e são colocadas em prática sem a aprovação dos gestores de topo, "tenho uma agenda aberta no salão, meu objetivo é encher a agenda, para isso, ligo para os clientes, envio whatsapp, preciso correr atrás" (colaborador do nível operacional).

Outra característica que reforça o modo generativo é o fato de os profissionais autônomos fazerem investimentos em equipamentos e cursos, sem o apoio financeiro da empresa "no ano passado (2014) investi mais de $\mathrm{R} \$ 10.000,00$ em equipamentos, minhas clientes gostam de novidades, preciso estar me atualizando sempre" (colaborador do nível operacional).

Nesse tipo de negócio, o comportamento intraempreendedor é desejável, especialmente entre os profissionais autônomos, já que a maioria do faturamento da empresa vem da produção deles (Venâncio et al, 2015).

\section{DA4: Gerente Integrador}

Considerando que o gerente integrador é sintetizador, categorizando ideias da equipe, sintetizando e informando-as à alta direção; e implementador: o gerente ajusta a estratégia, motiva e inspira a equipe a alcançá-la, foi possível identificar que a gerente administrativa busca atingir os objetivos estratégicos definidos no planejamento, porém frequentemente os caminhos adotados sofrem mudanças, a partir de ideias vindas principalmente da equipe, dessa forma a gerente administrativa atua de maneira sintetizadora (Floyd \& Wooldridge, 1992). Com foco na estratégia da empresa, a gerente observa diariamente como as ações são executadas na prática, seu trabalho está muito voltado ao contato com os colaboradores, de forma que sua percepção sobre as rotinas de trabalho é muito importante para os diretores, "Temos um plano estratégico, mas muita coisa ocorre no meio do caminho, semanalmente me reúno com a diretora da empresa, e levo até ela sugestões e ideias da equipe para serem colocadas em prática" (gerente administrativo).

Por outro lado, a gerente financeira trabalha de forma mais linear, restringe-se a traduzir as definições estratégicas em ações voltadas à situação financeira da empresa. Seus atos consolidam-se em um modo de trabalho implementador, que coloca em prática a estratégia conforme ela é deliberada sem grandes intervenções ou desvio de diretrizes. "Falando de financeiro, o que a diretora fala e eu coloco em prática (...) gosto de fazer as coisas ao "pé da letra"" (gerente financeira).

Essas duas formas de trabalho das gerentes corroboram o conceito de Floyd \& Wooldridge (1992), que explana o perfil de gerentes de nível intermediário, pode-se identificar a presença do comportamento integrador (sintetizador e implementador) no nível gerencial.

\subsection{Questão de Pesquisa e Proposição Teórica}

Considerando a questão de pesquisa norteadora deste estudo - Como ocorre o papel da gerência intermediária no processo de formação da estratégia?

E, considerando a proposição elaborada a partir do marco teórico - A formação da estratégia é integradora - middle-up-down quando o gerente intermediário desempenha um papel integrador (sintetizando a informação e implementando a estratégia deliberada) sendo autônomo e participativo simultaneamente, pode-se dizer a partir das evidências encontradas na coleta de dados e analisada por meio das dimensões de análise conceituais, que a proposição encontrou ressonância no caso estudado.

Foram encontradas evidências do processo de formação da estratégia formalizada sendo implementada não somente a partir das determinações do topo, mas também desde as interações proporcionadas pelo nível gerencial que é atuante. Essa atuação de papel integrador, desempenhada pelas gerentes, pode estar relacionada com uma das características do setor, que apresenta uma "relação próxima entre o receptor (cliente) e o prestador do serviço (cabeleireiro, manicure, esteticista), trata-se de um serviço de intenso toque e com grande intimidade, existe uma interação social próxima e amigável entre cliente e funcionário (Nogueira; Souza; Nunes, 2009; 
Ribeiro; Thiesen; Tinoco, 2013), exigindo da empresa essa atuação integradora e dinâmica.

A partir do entendimento que outras proposições podem ser estudadas e, considerando que no setor pesquisado prevalecem as empresas de pequeno porte, que efetuam tarefas em que a interação entre cliente, profissional autônomo e gestor é complexa, entende-se, também, embora não tenha sido objetivo inicial estudar os tipos de estratégia, que a estratégia que combina o tipo comando e racional (Hart, 1992) é adequada para organização de pequeno porte e de estrutura formal, típica do setor da beleza (ABIHPEC, 2014). Entende-se, ainda que o setor relacionado a ambientes dinâmicos (setor da beleza) se ajusta a combinação entre a formação da estratégia tipo comando e transacional.

\section{CONCLUSÃO}

A literatura sobre a formação de estratégia é democrática, já que várias formas são reconhecidas e aceitas (Mintzberg, Ahlstrand \& Lampel, 2009). Os estudos qualitativos ajudam a compreender o que motiva um ou outro modo de formação de estratégia. Assim, este estudo de caso teve como objetivo analisar o processo de formação estratégica e o papel do nível gerencial, nesse processo.

Percebeu-se que as estratégias são formadas de maneira integradora, o que caracteriza o estilo middle-up-down (Nonaka, 1988). Adicionalmente, identificou-se, de acordo com o framework integrativo de Hart (1992), três modos que evidenciam a formação da estratégia integradora: o comando, no qual a estratégia dirigida pelo líder ou por uma pequena equipe do topo; o transacional, em que por vezes o gestor de topo e os membros da equipe trabalham juntos na formação da estratégia, dirigidos por processos internos e em comum acordo; e o genérico, sendo que, neste caso, a estratégia é dirigida pela ação dos membros da equipe e o gestor apenas apoia a decisão.

A combinação de diferentes modos tende a melhorar o desempenho organizacional (Hart, 1992; Hart; Banbury, 1994). A pesquisa não teve como objetivo avaliar o desempenho da empresa, mas constatou-se que ela vem alcançando os objetivos traçados por meio das estratégias implementadas.Com relação aos papéis dos gerentes na formação da estratégia, encontrou-se duas gerentes, uma administrativa e outra financeira, ambas atuando de forma integradora (Floyd; Wooldridge, 1992), entretanto, a gerente administrativa atua de baixo para cima, de forma a sintetizar para os gestores de topo as informações coletadas com os colaboradores de nível operacional, e a gerente financeira atua de cima para baixo, como implementadora da estratégia deliberada. Suspeita-se que o papel assumido receba influência do tipo de atividade desempenhada. Ou seja, o setor da beleza e, mais especificamente, os salões de beleza apresentam uma dinâmica e uma troca de informações, conceitos, sutilezas, valores e subjetividades, que exigem do pessoal que trabalha no dia a dia da organização uma interação e uma capacidade de articular as decisões do dia a dia e se colocar no lugar de quem recebe o serviço (também muito específico) muito elevada (Fitzsimmons; Fitzsimmons, 2010).

Algumas limitações para o desenvolvimento deste estudo foram à falta de outros estudos de caso no mesmo segmento, para que possam ser avaliadas as possíveis diferenças entre as organizações pesquisadas. Como os estudos qualitativos com base em entrevista, este estudo pode conter um viés relativo à subjetividade dos respondentes e da interpretação dos resultados.

Como futuras linhas de investigação a partir deste estudo, sugere-se que novas pesquisas examinem como os profissionais autônomos podem desenvolver suas capacidades intraempreendedoras de modo a participarem mais efetivamente do processo de formação da estratégia. Propõe-se, também, novos estudos qualitativos que visem compreender de maneira mais aprofundada como as estratégias emergem no dia a dia dos salões de beleza e como influenciam no desempenho da empresa.

Do ponto de vista acadêmico, esta pesquisa colabora com os estudos sobre os processos de formação de estratégia e o papel do nível gerencial apresentando evidencias para melhor compreender o fenômeno observado, desde uma análise qualitativa.

A contribuição empresarial está relacionada ao setor estudado, o setor da beleza, o qual apresenta poucos estudos que evidenciem os fenômenos organizacionais e favoreçam o entendimento dos processos para alcançar uma gestão de excelência. Os resultados obtidos na pesquisa apontam que os salões de beleza possuem uma característica especial, a maior parte dos colaboradores é autônoma, tem seus recebimentos atrelados à produção, dessa forma fica explícita a importância desses profissionais no processo de formação da estratégia, podendo ser também eles os estrategistas (Whittington, 2007).

\section{REFERÊNCIAS}

Angonese, R., Lavarda, R. A. B. \& Lavarda, C. E. F. (2013) O processo de implementação da estratégia: um estudo segundo os modelos de Hart (1992). Revista Gestão \& Tecnologia, 13(1), 51-77.

\section{ASSOCIAÇÃO BRASILEIRA DA INDÚSTRIA DE HIGIENE PESSOAL, PERFUMARIA E COSMÉTICOS (2014). Panorama do Setor. São Paulo, 13, 2014-2015.}

Barney, J. B. \& Hesterly, W. S. (2007). Administração Estratégica e Vantagem Competitiva. Tradução Monica Rosemberg. Revisão técnica Pedro Zanni. São Paulo: Pearson Prentice Hall. 
Chandler, A. (1962). Strategy and structure. Cambrige: MIT Press.

Bispo, S. M.; Godoy, A. S. (2014). ETNOMETODOLOGIA: UMA PROPOSTA PARA PESQUISA EM ESTUDOS ORGANIZACIONAIS. DOI: 10.15600/16795350/rau. v12n2p108-135. Revista de Administração da Unimep-Unimep Business Journal, 12(2), 108-135.

Eisenhardt, K. M. (1989). Building theories from case study research. The Academy of Management Review, 14(4), 532-550.

Fitzsimmons, J. A.; Fitzsimmons, M. J. (2010). Administração de serviços: operações, estratégia e tecnologia da informação. 6. ed. Porto Alegre: Bookman.

Floyd, S. W.; Wooldridge, B. (1992). Middle Management Involvement in Strategy and Its Association with Strategic Type: A Research Note. Strategic Management Journal, Chichester, 13, Special Issue, 153-167.

Franzon, F., Oliveira, D. \& Lavarda, R. A. B. (2012). Atuação do gerente intermediário no processo de formulação e implantação da estratégia: um estudo de caso. Revista Brasileira de Administração Científica, 3(3), 128-146.

Gallas, J. C., Cancellier, E. L. P. L., Rossetto, C. R. \& Vargas, S. M. L. (2015). Comportamento Estratégico no Setor de Beleza e Estética Baseado na Tipologia de Miles e Snow. VII Encontro de estudos em estratégia. Brasília.

Godoi, C. K., Bandeira-de-Mello, R. \& Silva, A. B. (2006). Pesquisa qualitativa em estudos organizacionais: paradigmas, estratégias e métodos. São Paulo: Saraiva.

Hart, S. (1992). An integrative framework for strategymaking processes. Academy of Management Review, 17(2), 327-351.

Hart, S. \& Banbury, C. (1994). How strategy making processes can make a difference. Strategic Management Journal, 15(4), 251-269.

Kerlinger, F. N. (1979) Metodologia da pesquisa em ciências sociais: um tratamento conceitual. São Paulo: EPU/EDUSP.

Luz, C. L. M., Gobbo, G. \& Lavarda, R. B. A Participação do Gerente de Nível Intermediário no Processo de Implementação da Estratégia Considerando os Estudos de Floyd \& Wooldridge
(1992). Revista Iberoamericana de Estratégia, 12(4), 123-149, 2013.

Mantere, S. (2008) Role Expectations and Middle Manager Strategic Agency. Journal of Management Studies, 45(2), 294-316.

Martins, G. T. \& Lavarda, R. B. (2013) Modelo integrador de formação da estratégia: um estudo de caso. Revista Organizações em Contexto, 9(17) 125-153.

Martins, C., Venâncio, D. M., Fiates, G. G. S., Roman, D. J. \& Erdmann, R. H. (2014). Gestão de serviços em salões de beleza: do diagnóstico à melhoria de qualidade. Revista GEPROS, 9(3), 79-93.

Miles, R. E. \& Snow, C. C. (1978). Organizational Strategy, Structure and Process. New York: McGraw Hill.

Mintzberg, H., Ahlstrand, B. \& Lampel, J. (2009). Safári de estratégia: um roteiro pela selva do planejamento estratégico. Porto Alegre: Bookman.

Mintzberg, H. \& Waters, J. A. (1985). Of Strategies Deliberate and Emergent. Strategic Management Journal, 6(3), 257-272.

Nogueira, B. L. A., Souza, V. A. \& Nunes, J. H. (2009). Consumo e Apresentação do Self nos Salões: Análise Sociológica dos Serviços de Beleza e Higiene. In: CONGRESSO BRASILEIRO DE SOCIOLOGIA, 14, 2009, Rio de Janeiro. Anais do Congresso Brasileiro de Sociologia - Categoria sociólogos do futuro, 14. ed.. Rio de Janeiro, Brasil.

Nonaka, I. (1988). Toward middle-up-down management: Accelerating information creation. Sloan Management Review, 29(3), 9-18.

Ribeiro, J. L. D., Thiesen, J. P. K. \& Tinoco, M. A. C. (2013). Determinantes da satisfação e atributos da qualidade em serviços de salão de beleza. Produção Porto Alegre, 23(3), 609-624.

Santos, S. (2006). Nuestra América: reinventar um paradigma subalterno do reconhecimento e redistribuição. In: ___ A Gramática do Tempo: para uma nova cultura política. São Paulo: Cortez, 191-225.

Trochim, W. M. K. (1989). Outcome Pattern Matching and Program Theory. Evolution and Program Planning. 12(4), 355-66.

Vargo, S. L. \& Lusch, R. F. (2004). Evolving to a New Dominant Logic for Marketing. Journal of Marketing, 68, 1-17. 
Venâncio, D. M., Dutra, A., Fiates, G. G. S. \& Feuerschütte, S. G. (2015). Comprometimento organizacional: confrontando o comprometimento afetivo e o instrumental entre trabalhadores autônomos e efetivos de salões de beleza. Holos, 2(2) 169-182.
Whittington, R. (2007). Strategy practice and strategy process: family differences and the sociological eye. Organization studies, 28(10), 1575-86.

Zeithaml, V. A. \& Bitner, M. J. (2003). Marketing de Serviços: a Empresa com Foco no Cliente. 2. ed. Porto Alegre: Bookman.

Yin, R. (2015). Estudo de caso: planejamento e métodos. 5. ed. Porto Alegre: Bookman. 